\title{
SOME MULTIPLICATION THEOREMS FOR THE NÖRLUND MEAN
}

\section{BY FLORENCE M. MEARS}

Absolute summability for the series $\sum_{n=1}^{\infty} u_{n}$ by the Cesàro mean and by the Riesz mean have been defined by Fekete* and by Obrechkoff, $\dagger$ respectively. In each case, theorems for the multiplication of series summed by these means have been proved. $\ddagger$ The purpose of this paper is to establish a definition for absolute summability by the Nörlund mean, and to prove three multiplication theorems for this mean. Theorem 1 includes Mertens' theorem for convergent series and its extension for the Cesàro mean. Theorem 2 includes Cesàro's multiplication theorem. Theorem 3 includes the following theorem by M. J. Belinfante for the Cesàro mean.

If $\sum_{n=1}^{\infty} u_{n}$ is summable $C_{s}$ to $U$, and if $\sum_{n=1}^{\infty} v_{n}$ is summable $C_{r}$ to $V$, and bounded $C_{r-1},(s \geqq 0, r \geqq 1)$, the product series $\sum_{n=1}^{\infty} w_{n}$ is summable $C_{r+s}$ to $U V . \S$

For any given series $\sum_{k=1}^{\infty} u_{k}$, with terms real or complex, form the sequence $\left\{U_{k}\right\}$, where $U_{k}=\sum_{n=1}^{k} u_{n}$. Let $\left\{a_{n}\right\}$ be a sequence of positive numbers, and let $A_{k}=\sum_{n=1}^{k} a_{n}$. The series $\sum_{k=1}^{\infty} u_{k}$ is said to be summable to $U^{\prime}$ by the Nörlund mean $A$ if

$$
\lim _{n \rightarrow \infty} U_{n}^{\prime}=\lim _{n \rightarrow \infty} \frac{\sum_{k=1}^{n} a_{n-k+1} U_{k}}{A_{n}}
$$

exists and is equal to $U^{\prime}$. If $\sum_{k=1}^{\infty} u_{k}^{\prime}$, where $u_{n}^{\prime}=U_{n}^{\prime}-U_{n-1}^{\prime}$, is absolutely convergent, we shall say that $\sum_{k=1}^{\infty} u_{k}$ is absolutely summable $A$. We shall assume that $\lim _{n \rightarrow \infty}\left(a_{n} / A_{n}\right)=0$; then $A$ is a regular method of summation.\|

* Matematikai és Természettudományi Értesitö, vol. 32 (1914), pp. 389425.

† Comptes Rendus, vol. 185 (1928), pp. 215-217.

$\ddagger$ For discussion and references, see Kogbetliantz, Mémorial des Sciences Mathématiques, No. 51.

$\S$ Koninklijke Akademie te Amsterdam, Verslag, vol. 32 (1923), pp. 177189.

T Riesz, Proceedings of the London Mathematical Society, (2), vol. 22 (1923), p. 412.

|| Riesz, loc. cit. 
We shall consider also the series $\sum_{k=1}^{\infty} v_{k}$, and $\sum_{k=1}^{\infty} w_{k}$, the Cauchy product of series $\sum_{k=1}^{\infty} u_{k}$ and $\sum_{k=1}^{\infty} v_{k}$; we have the corresponding sequences $\left\{V_{k}\right\}$ and $\left\{W_{k}\right\}$.

We shall assume that we have also a regular Nörlund mean, $B$, defined by $\left\{b_{k}\right\}$, a sequence of positive numbers. We shall form the Nörlund means, $C$, defined by $\left\{c_{n}\right\}=\left\{\sum_{k=1}^{n} a_{k} b_{n-k+1}\right\}$, and $D$, defined by $\left\{d_{n}\right\}=\left\{\sum_{k=1}^{n} A_{k} b_{n-k+1}\right\}$.

Theorem 1. If $\sum_{k=1}^{\infty} u_{k}$ is summable $A$ to $U^{\prime}$, and in addition, absolutely summable $A$, and if $\sum_{k=1}^{\infty} v_{k}$ is summable $B$ to $V^{\prime}$, then $\sum_{k=1}^{\infty} w_{k}$ is summable $C$ to $U^{\prime} V^{\prime}$.

Proof. We shall prove the theorem first with the assumption that $V^{\prime}=0$. Let

$$
\begin{gathered}
U_{n}^{\prime}=\frac{1}{A_{n}} \sum_{k=1}^{n} a_{k} U_{n-k+1}, \quad V_{n}^{\prime}=\frac{1}{B_{n}} \sum_{k=1}^{n} b_{k} V_{n-k+1}, \\
W_{n}^{\prime}=\frac{1}{C_{n}} \sum_{k=1}^{n} c_{k} W_{n-k+1} ;
\end{gathered}
$$

let $\sum_{k=1}^{\infty} u_{k}^{\prime}, \sum_{k=1}^{\infty} v_{k}^{\prime}$, and $\sum_{k=1}^{\infty} w_{k}^{\prime}$ be the corresponding series; then

$$
\begin{aligned}
\left|W_{n}^{\prime}\right| \leqq \frac{1}{C_{n}}\{\mid & u_{1}^{\prime}|| \sum_{l=1}^{n} c_{l} V_{n-l+1} \mid \\
& \left.+\sum_{k=2}^{n}\left[\left|u_{k}^{\prime}\right|\left|\sum_{l=1}^{n-k} V_{l} S+A_{k} b_{1} V_{n-k+1}\right|\right]\right\},
\end{aligned}
$$

where

$$
S=A_{k} b_{n-k-l+2}+\sum_{p=k+1}^{n-l+1} a_{p} b_{n-l-p+2}
$$

Hence

$$
\begin{aligned}
\left|W_{n}^{\prime}\right| \leqq & \frac{1}{C_{n}}\left\{\left|u_{1}^{\prime}\right|\left|\sum_{l=1}^{n} c_{l} V_{n-l+1}\right|\right. \\
& +\sum_{k=2}^{n}\left[\left|u_{k}^{\prime}\right| A_{k}\left|\sum_{l=1}^{n-k+1} b_{n-k-l+2} V_{l}\right|\right] \\
& \left.+\sum_{k=2}^{n-1}\left[\left|u_{k}^{\prime}\right|\left|\sum_{l=1}^{n-k} \sum_{p=k+1}^{n-l+1} a_{p} b_{n-l-p+2} V_{l}\right|\right]\right\} \\
= & P_{n}\left|u_{1}^{\prime}\right|+\sum_{k=2}^{n}\left[\left|u_{k}^{\prime}\right| Q_{n k}\right]+\sum_{k=2}^{n-1}\left[\left|u_{k}^{\prime}\right| R_{n k}\right]
\end{aligned}
$$


Since $C$ includes $B$,

$$
\lim _{n \rightarrow \infty} P_{n}=0 \text {. }
$$

For $2 \leqq k \leqq n$,

Therefore

$$
\begin{aligned}
& Q_{n k}<\frac{A_{k}\left|\sum_{l=1}^{n-k+1} b_{n-k-l+2} V_{l}\right|}{\sum_{l=k}^{n} A_{l} b_{n-l+1}} \\
& <\frac{A_{l}\left|\sum_{l=1}^{n-k+1} b_{n-k-l+2} V_{l}\right|}{A_{k} \sum_{l=k}^{n} b_{n-l+1}}=\left|V_{n-k+1}^{\prime}\right| .
\end{aligned}
$$

$$
\begin{aligned}
\sum_{k=2}^{n} Q_{n k}\left|u_{k}^{\prime}\right| & <\sum_{k=2}^{n}\left|V_{n-k+1}^{\prime}\right|\left|u_{k}^{\prime}\right| \\
& =\sum_{k=2}^{\nu}\left|V_{n-k+1}^{\prime}\right|\left|u_{k}^{\prime}\right|+\sum_{k=\nu+1}^{n}\left|V_{n-k+1}^{\prime}\right|\left|u_{k}^{\prime}\right|
\end{aligned}
$$

where $\nu$ may be chosen so that $\nu$ and $n-\nu$ become infinite with $n$. Since $\lim _{n \rightarrow \infty}\left|V_{n}^{\prime}\right|=0$, for any $\epsilon, \nu$ and $n$ may be chosen sufficiently large so that

$$
\sum_{k=2}^{n}\left[Q_{n k}\left|u_{k}^{\prime}\right|\right]<\epsilon
$$

For $2 \leqq k \leqq n-1$, we have

$$
\begin{aligned}
R_{n k} \leqq & \frac{\sum_{l=1}^{n-2} a_{n-l+1} B_{l}\left|V_{l}^{\prime}\right|}{C_{n}} \\
& =\left[\frac{1}{C_{n}} \sum_{l=1}^{n-2} a_{n-l+1} B_{l}\right]\left[\sum_{p=1}^{n-2} \frac{a_{n-p+1} B_{p}\left|V_{p}^{\prime}\right|}{\sum_{l=1}^{n-2} a_{n-l+1} B_{l}}\right] \\
& <\sum_{p=1}^{n-2} \frac{a_{n-p+1} B_{p}\left|V_{p}^{\prime}\right|}{\sum_{l=1}^{n-2} a_{n-l+1} B_{l}}=V_{n-2}^{\prime \prime},
\end{aligned}
$$

* Nörlund, Lunds Universitet, Årsskrift, (2), vol. 16 (1919), No. 3. 
where $V_{n-2}^{\prime}$ is the $(n-2)$ th term of the sequence obtained when $\left\{\left|V_{p}^{\prime}\right|\right\}$ is summed by the matrix transformation $t_{n p}$, where

$$
t_{n p}=\frac{a_{n-p+3} B_{p}}{\sum_{l=1}^{n} a_{n-l+3} B_{l}}
$$

for $p \leqq n$, and $t_{n p}=0$ for $p>n$.

This transformation is regular, since $A$ is regular; it follows that $\lim _{n \rightarrow \infty} V_{n-2}^{\prime \prime}=0$, and that for any $\epsilon$, we may find $n$ sufficiently large so that

$$
R_{n k}<\epsilon .
$$

From (1), (2), (3), and the fact that $\sum_{k=1}^{\infty}\left|u_{k}^{\prime}\right|$ converges, it follows that $\lim _{n \rightarrow \infty}\left|W_{n}^{\prime}\right|=0$. This proves the theorem for $V^{\prime}=0$.

If $V^{\prime} \neq 0$, we consider the sequence $\left\{V_{n}-V^{\prime}\right\}$; this sequence is summed by $B$ to 0 . Hence the Cauchy product of $\sum_{n=1}^{\infty} u_{n}$ by $\left[v_{1}-V^{\prime}\right]+\sum_{n=2}^{\infty} v_{n}$ is summed by $C$ to 0 ; that is,

$$
\lim _{n \rightarrow \infty}\left[W_{n}^{\prime}-V^{\prime} \frac{\sum_{k=1}^{n} c_{k} U_{n-k+1}}{C_{n}}\right]=0 .
$$

Since $C$ includes $A$,

$$
\lim _{n \rightarrow \infty} \frac{\sum_{k=1}^{n} c_{k} U_{n-k+1}}{C_{n}}=U^{\prime}
$$

therefore $\lim _{n \rightarrow \infty} W_{n}^{\prime}=U^{\prime} V^{\prime}$.

Theorem 2. If $\sum_{k=1}^{\infty} u_{k}$ is summable $A$ to $U^{\prime}$, and if $\sum_{k=1}^{\infty} v_{k}$ is summable $B$ to $V^{\prime}$, then $\sum_{k=1}^{\infty} w_{k}$ is summable $D$ to $U^{\prime} V^{\prime}$.

Proof. We have

$$
W_{n}^{\prime}=\frac{1}{D_{n}} \sum_{k=1}^{n} d_{k} W_{n-k+1}=\sum_{k=1}^{n} g_{n k} U_{k}^{\prime} V_{n-k+1}^{\prime},
$$

where $g_{n k}=A_{k} B_{n-k+1} / D_{n}$ for $k \leqq n$, and $g_{n k}=0$ for $k>n$. 
Since $A$ and $B$ are regular, this method of summation is regular and $\lim _{n \rightarrow \infty} g_{n, n-k+1}=0$; it follows that*

$$
\lim _{n \rightarrow \infty} \sum_{k=1}^{n} g_{n k} U_{k}^{\prime} V_{n-k+1}^{\prime}=U^{\prime} V^{\prime}
$$

which completes the proof.

For the proof of Theorem 3 we require the following lemma.

LEMma. If $\left\{X_{n}\right\}$ and $\left\{\left[\sum_{n}^{n} B_{k=1} B_{k} y_{n-k+1}\right] / B_{n}\right\}$ converge to $X$ and $Y$, respectively, and if $\left\{\left[\sum_{k=1}^{n} b_{k} y_{n-k+1}\right] / b_{n}\right\}$ is bounded, then

$$
\lim _{n \rightarrow \infty}\left\{\sum_{k=1}^{n} a_{n k} X_{k} \frac{\sum_{l=1}^{n-k+1} b_{l} y_{n-k-l+2}}{b_{n-k+1}}\right\}=X Y,
$$

provided that (a) $\lim _{n \rightarrow \infty} a_{n k}=0$; (b) $\sum_{k=1}^{n}\left|a_{n k}\right|<M$ for all $n$, where $M$ is a positive constant; (c) $T^{\prime}$ includes $T$, where $T^{\prime}$ and $T$ are triangular matrix transformations defined by $t_{n k}^{\prime}=a_{n, n-k+1}$ and $t_{n k}=b_{k} / B_{n}$.

Proof. Let

$$
\frac{\sum_{l=1}^{n-k+1} b_{l} y_{n-k-l+2}}{b_{n-k+1}}=y_{n-k+1}^{\prime}
$$

and let $a_{n k} y_{n-k+1}^{\prime}=c_{n k}$. Let $Z_{n}=\sum_{k=1}^{n} c_{n k} X_{k}$. From (a), (b), and (c), it follows that $\lim _{n \rightarrow \infty} c_{n k}=0, \sum_{k=1}^{n}\left|c_{n k}\right|<M^{\prime}$, where $M^{\prime}$ is a positive constant, and $\lim _{n \rightarrow \infty} \sum_{k=1}^{n} c_{n k}=Y$. Choose $p$ such that for a given $\epsilon>0,\left|X_{k}-X\right|<\epsilon /\left(2 M^{\prime}\right)$ when $k>p$. For $k \leqq p$, $\left|X_{k}-X\right|<L$. Then

$$
\begin{aligned}
\left|Z_{n}-X \sum_{k=1}^{n} c_{n k}\right| & \leqq \sum_{k=1}^{p}\left|c_{n k}\right|\left|X_{k}-X\right|+\sum_{k=p+1}^{n}\left|c_{n k}\right|\left|X_{k}-X\right| \\
& \leqq L \sum_{k=1}^{p}\left|c_{n k}\right|+\frac{\epsilon}{2 M^{\prime}}\left|c_{n k}\right| .
\end{aligned}
$$

Choose $N>p$, and such that $\left|c_{n k}\right|<\epsilon /(2 p L)$ for $n>N$. Then for $n>N,\left|Z_{n}-X \sum_{k=1}^{n} c_{n k}\right|<\epsilon$, which proves the lemma.

* Dale, American Journal of Mathematics, vol. 47 (1925), p. 82. 
THEOREM 3. If $\sum_{k=1}^{\infty} u_{k}$ is summable $A$ to $U^{\prime}$ and $\sum_{k=1}^{\infty} v_{k}$ summable $B$ to $V^{\prime}$, and if

$$
\left|\frac{b_{n} v_{1}+\cdots+b_{1} v_{n}}{b_{n}}\right|<M,
$$

then $\sum_{k=1}^{\infty} w_{k}$ is summable $C$ to $U^{\prime} V^{\prime}$.

Proof. Consider the triangular matrix definition

$$
a_{n k}=\frac{A_{k} b_{n-k+1}}{A_{1} b_{n}+\cdots+A_{n} b_{1}} .
$$

This definition satisfies the three conditions of the lemma, for

$$
\frac{A_{k} b_{n-k+1}}{\sum_{l=1}^{n} A_{l} b_{n-l+1}}<\frac{A_{k} b_{n-k+1}}{\sum_{l=k}^{n} A_{l} b_{n-l+1}}<\frac{b_{n-k+1}}{\sum_{l=k}^{n} b_{n-l+1}} ;
$$

$$
\begin{aligned}
& \sum_{k=1}^{n}\left|a_{n k}\right|=1 ; \\
& A^{\prime}=C^{\prime} B^{\prime},
\end{aligned}
$$

where $A^{\prime}, B^{\prime}$, and $C^{\prime}$ are triangular matrix definitions with

$$
a_{n k}^{\prime}=a_{n, n-k+1}, \quad b_{n k}^{\prime}=\frac{b_{k}}{B_{n}}, \quad c_{n k}^{\prime}=\frac{a_{n-k+1} B_{k}}{\sum_{l=1}^{n} A_{l} b_{n-l+1}} .
$$

The definition $C^{\prime}$ is regular. The theorem follows immediately from this lemma.

The George Washington University 